\title{
Rapid Cyclogenesis from a Mesoscale Frontal Wave on an Atmospheric River: Impacts on Forecast Skill and Predictability during Atmospheric River Landfall
}

\author{
Andrew C. MARTin, ${ }^{a}$ F. MARTIN RALPH, AND ANNA Wilson \\ Center for Western Weather and Water Extremes, and Climate, Atmospheric Science, and Physical Oceanography Division, \\ Scripps Institution of Oceanography, La Jolla, California \\ LAUREL DeHAAN \\ Climate, Atmospheric Science, and Physical Oceanography Division, Scripps Institution of Oceanography, La Jolla, \\ California \\ BRIAN KAWZENUK \\ Center for Western Weather and Water Extremes, and Climate, Atmospheric Science, and Physical Oceanography Division, \\ Scripps Institution of Oceanography, La Jolla, California
}

(Manuscript received 12 November 2018, in final form 17 May 2019)

\begin{abstract}
Mesoscale frontal waves have the potential to modify the hydrometeorological impacts of atmospheric rivers (ARs). The small scale and rapid growth of these waves pose significant forecast challenges. We examined a frontal wave that developed a secondary cyclone during the landfall of an extreme AR in Northern California. We document rapid changes in significant storm features including integrated vapor transport and precipitation and connect these to high forecast uncertainty at 1-4-days' lead time. We also analyze the skill of the Global Ensemble Forecast System in predicting secondary cyclogenesis and relate secondary cyclogenesis prediction skill to forecasts of AR intensity, AR duration, and upslope water vapor flux in the orographic controlling layer. Leveraging a measure of reference accuracy designed for cyclogenesis, we found forecasts were only able to skillfully predict secondary cyclogenesis for lead times less than $36 \mathrm{~h}$. Forecast skill in predicting the large-scale pressure pattern and integrated vapor transport was lost by 96-h lead time. For lead times longer than $36 \mathrm{~h}$, the failure to predict secondary cyclogenesis led to significant uncertainty in forecast AR intensity and to long bias in AR forecast duration. Failure to forecast a warm front associated with the secondary cyclone at lead times less than $36 \mathrm{~h}$ caused large overprediction of upslope water vapor flux, an important indicator of orographic precipitation forcing. This study highlights the need to identify offshore mesoscale frontal waves in real time and to characterize the forecast uncertainty inherent in these events when creating hydrometeorological forecasts.
\end{abstract}

\section{Introduction}

\section{a. Event significance}

At 1800 UTC 10 December 2014, an extreme (Ralph et al. 2019a) atmospheric river (AR) struck the Russian River watershed (RRW) in California (CA), causing the

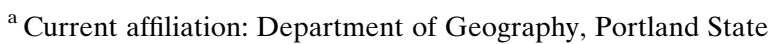
University, Portland, Oregon.
}

Corresponding author: Andrew C. Martin,mc@ucsd.edu river to exceed flood stage near the flood-vulnerable town of Guerneville. Figures $1 \mathrm{a}$ and $1 \mathrm{~b}$ show the AR as its southeastern edge is striking the RRW using integrated water vapor $(\mathrm{mm})$ and the magnitude of integrated vapor transport (IVT; $\mathrm{kg} \mathrm{m}^{-1} \mathrm{~s}^{-1}$ ) diagnosed from ERA-Interim (Dee et al. 2011), respectively. Major flood-related damage did not occur, but had crest height been a few feet higher, this event would have been similar in magnitude to the historic AR-driven floods at Guerneville of February 1998 and February 2004 (Ralph et al. 2006).

Forecasts of this event predicted the landfall of a strong to extreme AR and associated heavy precipitation and 

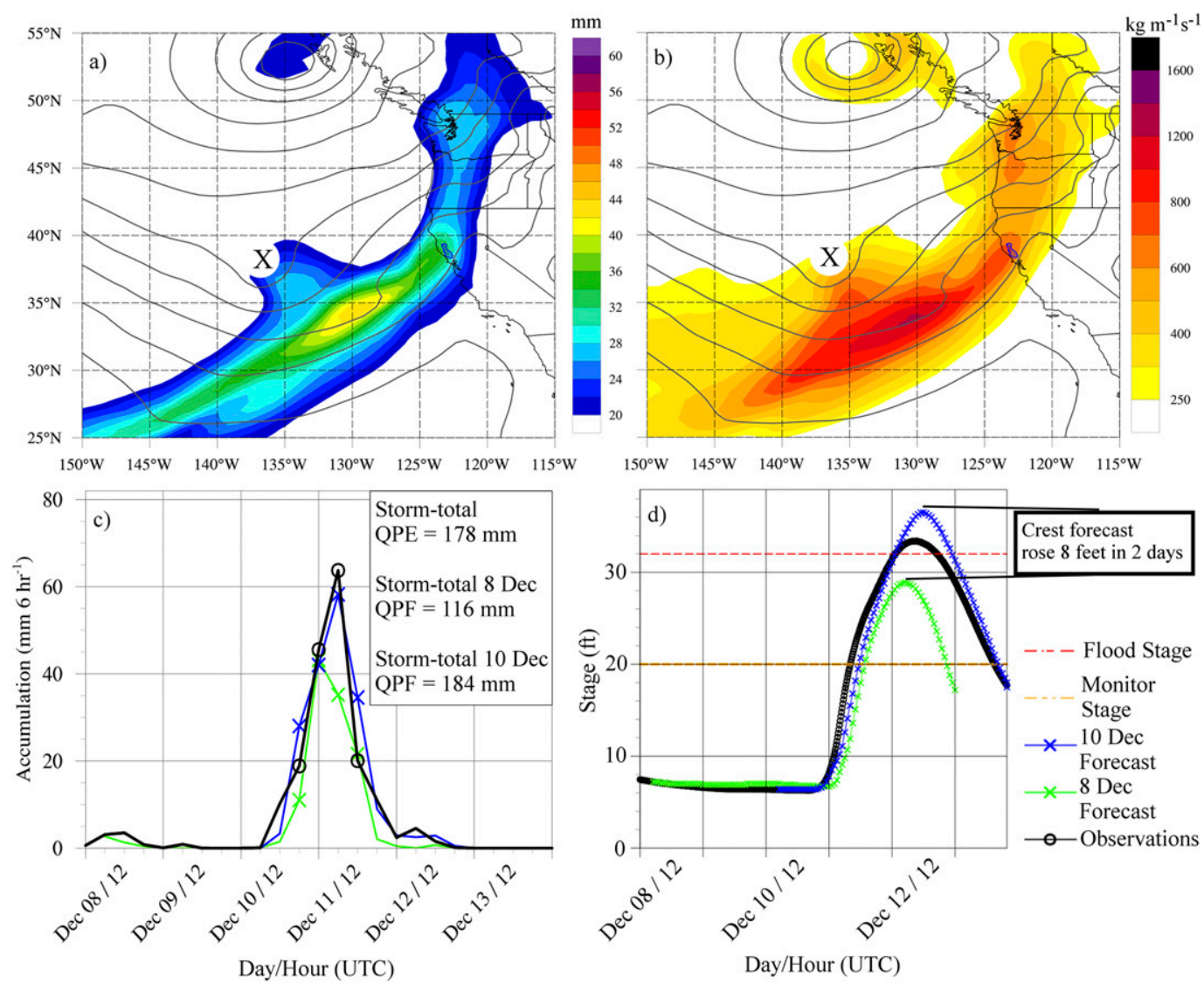

FIG. 1. (a) IWV (mm; shaded) and SLP (hPa; contours every $4 \mathrm{hPa}$ from 974 to $1018 \mathrm{hPa}$ ) from ERA-Interim valid at 0000 UTC 11 Dec 2014. RRW is shown by blue outline and interior shading. The "X" marks the location of the MFW. (b) As in (a), but shading depicts IVT $\left(\mathrm{kg} \mathrm{m}^{-1} \mathrm{~s}^{-1}\right)$. (c) The 6-hourly accumulated RRW-mean areal QPF issued by CNRFC at 1200 UTC 8 Dec (mm; green) and 1200 UTC 10 Dec 2014 (mm; blue) and the CNRFC QPE (mm; black). Time on ordinate axis refers to forecast or QPE valid time. Inset contains storm-total (1200 UTC 10 Dec-1200 UTC 13 Dec 2014) accumulated RRW-mean precipitation from each time series. (d) Guerneville river-stage forecast issued by CNRFC near 1200 UTC 8 Dec (mm; green) and near 1200 UTC 10 Dec (mm; blue) and observations from the river gauge (mm; black). Shown for reference are the monitor (orange) and flood (red) stages.

runoff. It is not uncommon to correctly predict $\mathrm{AR}$ landfalls up to 1 week in advance (Wick et al. 2013; Lavers et al. 2016), but important details in the forecasts of this event changed significantly in the $72 \mathrm{~h}$ before AR landfall. Figure 1c displays the RRW-mean, 6-hourly accumulated quantitative precipitation forecasts (QPF; mm) issued by the California-Nevada River Forecast Center (CNRFC) approximately 60 and $12 \mathrm{~h}$ before AR landfall, on 8 and 10 December, respectively. The CNRFC quantitative precipitation estimate (QPE; $\mathrm{mm}$ ) is provided as an estimate of the actual accumulated precipitation.

The forecasts issued on 8 December predicted lowerthan-observed peak 6-hourly precipitation with significant accumulation $\left[>10 \mathrm{~mm}(6 \mathrm{~h})^{-1}\right]$ arriving and ending earlier than observed. Figure $1 \mathrm{~d}$ similarly shows the CNRFC streamflow forecasts issued on 8 and
10 December, with observed river stage at Guerneville also provided. Following the attributes of the 8 December QPF, forecast river stage issued on 8 December crested slightly earlier than observed and called for a crest near $29 \mathrm{ft}(1 \mathrm{ft} \approx$ $0.305 \mathrm{~m}$ ). This crest was $4 \mathrm{ft}$ lower than the observed crest and below flood stage. QPF issued on 10 December included peak 6-hourly accumulation very close in magnitude to peak QPE and timed correctly. Of note, QPF just after AR landfall at 0600 UTC 11 December was approximately $10 \mathrm{~mm}$ higher than observed, with a significant overforecast also visible just after the event peak QPE at 0000 UTC 12 December. In part driven by these precipitation forecast errors during the intensification and cessation periods of the event, the 10 December river-stage forecast (Fig. 1d) called for a crest just above $36 \mathrm{ft}$, or $4 \mathrm{ft}$ higher than observed and near the historically significant events reported by Ralph et al. (2006). 
Between 8 and 10 December, the expected river crest rose approximately $8 \mathrm{ft}$, a large change in the expected outcome in a short amount of time. Figures $1 \mathrm{a}$ and $1 \mathrm{~b}$ also show the pressure reduced to mean sea level pressure (SLP; $\mathrm{hPa}$ ) from ERA-Interim near the time of AR landfall in the RRW. Visible near $40^{\circ} \mathrm{N}, 137^{\circ} \mathrm{W}$ is a depression in SLP near the poleward periphery of the AR. This depression grew from a mesoscale frontal wave (MFW), initially detected in the ERA-Interim SLP field $12 \mathrm{~h}$ prior. Analysis presented in later sections will demonstrate that this MFW eventually developed a secondary extratropical cyclone and that its presence had significant impacts on forecasts of the landfalling AR, including on their accuracy and uncertainty in the 3 days prior to landfall.

\section{b. Background}

ARs are a major driver of floods in the western United States (Ralph et al. 2006; Dettinger et al. 2011; Neiman et al. 2011; Ralph and Dettinger 2011; Neiman et al. 2013). Skill in weather forecasts of ARs has been documented, primarily at the synoptic scales where ARs are a recognizable feature of the extratropical circulation (Wick et al. 2013; Nayak et al. 2014; Guan and Waliser 2015; DeFlorio et al. 2018). Mesoscale phenomena also create challenges when forecasting AR impacts, including precipitation (Leung and Qian 2009; Neiman et al. 2009; Ralph et al. 2013; Martin et al. 2018). One such mesoscale phenomena is the mesoscale frontal wave (Parker 1998).

Ralph et al. (2011) demonstrated that a persistent MFW lengthened atmospheric river conditions during landfall of an AR in Washington, directly leading to large rainfall totals in the affected area. Neiman et al. (2016) documented the case of three consecutive MFWs propagating along the boundary of an AR making landfall in Northern CA. The three waves acted to reinforce baroclinicity in the region of the existing AR and cold front, leading to the longest-duration AR on record at the CA Department of Water Resources Atmospheric River Observatory (ARO; White et al. 2013). Ludwig et al. (2015) discussed a MFW in the North Atlantic Ocean and followed its development into a secondary cyclone. The secondary cyclone strengthened and supported destructive wind speeds far to the east of the climatological storm track. This storm, named Kyrill (2007), caused extensive wind damage in northern and central Europe. While Ludwig et al. did not address the existence of an AR near the secondary cyclone, analysis presented therein shows features common to AR, including a warm and moist filamentary corridor to the equatorward side of the front and nearly moist neutral stratification.
The studies to date concerning MFWs, ARs and secondary cyclones demonstrate that when MFWs or secondary cyclones develop near landfalling ARs, the hydrometeorological impacts of the AR can be greatly modified. Ralph et al. (2011), Ludwig et al. (2015), and Neiman et al. (2016) highlight a few such impacts including AR duration, accumulated precipitation, and wind speed. We can use quasigeostrophic arguments to further anticipate that MFWs and secondary cyclones forming near the periphery of an existing AR may influence

- the precipitation rate by inducing vertical motion,

- the horizontal water vapor flux by deformation of the local pressure gradient or modification of the water vapor budget (convergence and/or precipitation terms), and

- the tropospheric freezing level by modifying the curvature of the flow near the baroclinic zone and inducing local anomalies in temperature advection.

All are important hydrometeorological variables, used by forecasters in the western United States and elsewhere to predict overland streamflow and the risk of flooding. However, secondary cyclones and their MFW precursors remain much more difficult to forecast than the larger-scale AR (Hewson 2009). MFWs may be poorly detected by modern observing systems, especially over oceans, owing to their small scale (widths of approximately hundreds of kilometers). Further, development of the incipient or mesoscale wave to a secondary cyclone cannot be assumed. The role of the large-scale environment and local physical processes in spurring development is not fully established (Renfrew et al. 1997; Parker 1998; Fink et al. 2012). Failure to accurately predict MFWs and secondary cyclones may thus represent a limiting factor to the skill in predicting the hydrometeorological impacts of some ARs.

\section{c. Goals}

This study documents the impacts of the AR introduced in the previous section and the role of the MFW in modulating them. It will also investigate forecast skill by the Global Ensemble Forecast System (GEFS) model in predicting the evolution of the MFW into a secondary cyclone while relating that skill to the accuracy and uncertainty in forecasts of the landfalling AR. The data sources and methods of analysis used are presented in section 2. Section 3 presents an overview of the event at the synoptic scale and locally within the RRW. Section 4 discusses the skill of GEFS in forecasting the cyclogenesis event and relates this to landfalling-AR forecasts. Evidence 
is presented that failure to identify a developing warm front associated with the secondary cyclone may have led to significant overprediction in the hydrometeorologically significant variable bulk upslope flux of water vapor at short forecast lead times. Section 5 discusses the major findings of this study.

\section{Data and methods}

\section{a. Observations and model analyses}

\section{1) THE ATMOSPHERIC RIVER OBSERVATORY}

NOAA and the CA Department of Water Resources jointly operate an ARO consisting of two individual stations, Bodega Bay and Cazadero, as part of the Enhanced Flood Response and Emergency Preparedness (EFREP) network (White et al. 2013). The ARO continuously measures several atmospheric variables. A few will be summarized here.

- 449-MHz wind-profiling radar: A wind-profiling radar is located approximately $100 \mathrm{~m}$ inland from the coast at Bodega Bay. The radar returns hourly estimates of the vertical profile of horizontal wind speed and direction from the surface to approximately $5 \mathrm{~km}$ above ground level, at a vertical resolution of approximately $100 \mathrm{~m}$.

- Integrated water vapor and bulk upslope vapor flux: Integrated water vapor (IWV) is calculated via the occultation method using the GPS Trimble receiver at Bodega Bay. Neiman et al. (2002, 2009) and Ralph et al. (2013) demonstrated that orographic precipitation at Cazadero strongly responds to the bulk upslope flux of water vapor (BUF) in an orographic precipitation controlling layer, located between 750 and $1250 \mathrm{~m}$ MSL. Rainfall rate at Cazadero responds in nearinstantaneous fashion to changes in BUF, with rainfall increasing when BUF increases. BUF is calculated using IWV from the GPS receiver and wind speed and direction from the $449-\mathrm{MHz}$ radar following the method of Neiman et al. (2002).

- Mountaintop precipitation: Cazadero is located approximately $35 \mathrm{~km}$ north of Bodega Bay at an elevation of approximately $478 \mathrm{~m}$. A tipping-bucket rain gauge at Cazadero provides a measurement of precipitation accurate to $0.254 \mathrm{~mm}$ and updated every minute. All ARO data were accessed from NOAA via https://www.esrl.noaa.gov/psd/data.

\section{2) ERA-INTERIM}

We used ERA-Interim (Dee et al. 2011) to identify large-scale meteorological features over the northeast Pacific Ocean and to describe the sequence of events concerning the AR, MFW, and secondary cyclone. ERA-Interim three-dimensional upper-air variables, valid every $6 \mathrm{~h}$, were downloaded from the NCAR research data archive at https://rda.ucar.edu/datasets/ ds627.0/. ERA-Interim is disseminated on a global regular latitude-longitude grid with a resolution of approximately $0.7^{\circ}$ latitude. The ERA-Interim variables zonal wind, meridional wind, geopotential height and specific humidity were used to diagnose IVT following Eq. (6) from Cordeira et al. (2013). ERA-Interim SLP was also used subjectively to detect the MFW and secondary cyclone (see section 2c under "Cyclone detection").

\section{3) GFS AnAlysis}

The GFS Grid 4 analysis on a global $0.5^{\circ}$ regular latitude-longitude grid was substituted for direct observation of the atmospheric state when calculating forecast errors and in some cases when visualizing meteorological features. GFS analysis IVT and SLP were calculated and interpreted as for ERA-Interim. GFS Analyses were accessed from the National Center for Atmospheric Research (NCAR) Research Data Archive (https://rda.ucar.edu/datasets/ds084.6/).

\section{4) CNRFC QUANTITATIVE PRECIPITATION ESTIMATES}

QPE, provided by the CNRFC via https:// www.cnrfc.noaa.gov/ on a 4-km grid over CA at a 6-hourly time interval, were used to evaluate the accumulated precipitation and 6-hourly precipitation time series during the event.

\section{5) USGS HYDROLOGIC UNIT GEOREFERENCED POLYGONS}

RRW-mean quantities were found using the U.S. Geological Survey (USGS) hydrologic unit code level 8 georeferenced polygon. For the relevant variable and data product grid (e.g., QPE on the CNRFC $4 \mathrm{~km}$ grid or IVT on the GFS analysis $0.5^{\circ}$ latitude-longitude grid), RRW mean was found by the arithmetic mean of all polygon interior grid points.

\section{6) USGS STREAm GAUGE AT GUERNEVILLE, CA}

River stage for the lower Russian River was observed at Guerneville, CA, by the permanent USGS gauging station (GUERN). GUERN data were obtained from the USGS (https://waterdata.usgs.gov/ca/nwis/uv/?site_ no $=11467002)$.

\section{7) OPC SURFACE ANALYSIS}

The NOAA Ocean Prediction Center (OPC) 6-hourly surface analysis charts were accessed to confirm the 
secondary cyclone and its impact on nearby frontal zones. OPC surface analysis images were accessed from $\mathrm{ftp} / / /$ nomads.ncdc.noaa.gov/12/ncep_charts/.

\section{b. Forecasts}

\section{1) Global Ensemble Forecast System}

GEFS forecasts are produced daily by the NOAA National Centers for Environmental Prediction (NCEP) and updated every $6 \mathrm{~h}$. GEFS forecasts valid for the period from 0600 UTC 10 December through 0600 UTC 12 December with forecast lead time up to $168 \mathrm{~h}$ were downloaded from the I THORPEX Interactive Grand Global Ensemble (TIGGE) archive at https:// www.ecmwf.int/en/research/projects/tigge. Operational GEFS forecasts issued during the period investigated here included one control forecast and 20 perturbed ensemble members on a $1^{\circ}$ latitude $\times 1^{\circ}$ longitude global grid. Output from TIGGE was bilinearly regridded to the GFS analysis grid. The isobaric surfaces $1000,925,850,700,500$, and $300 \mathrm{hPa}$ were retained. GEFS RRW-mean BUF was calculated as described in section 2a ("Integrated water vapor and bulk upslope vapor flux") by substituting precipitable water for IWV and wind speed and direction on the $925-\mathrm{hPa}$ isobaric surface for the controlling layer mean wind. The hydrostatic equation was applied to ARO 449-MHz wind-profiling radar heights and the ARO surface pressure to confirm that the $925-\mathrm{hPa}$ isobaric surface was within the orographic controlling layer for the duration of this event.

\section{2) CNRFC RIVER STAGE AT GUERNEVILle, CA}

Operational forecasts of river stage (an operational streamflow forecast product) at GUERN were downloaded from CNRFC via https://www.cnrfc.noaa.gov/.

\section{3) CNRFC QUANTITATIVE PRECIPITATION FORECASTS}

QPF, created operationally by CNRFC, were accessed on their native 4-km grid via https://www.cnrfc.noaa.gov/.

\section{c. AR conditions and other variables}

\section{1) AR CONDITIONS}

AR conditions for the RRW were defined following Ralph et al. (2013). The authors define AR conditions when thresholds of IWV $\geq 2.0 \mathrm{~cm}$ and $\mathrm{BUF} \geq$ $25 \mathrm{~cm} \mathrm{~m} \mathrm{~s}^{-1}$ are met for more than 8 consecutive hours. Herein the magnitude of BUF is used to indicate AR-condition strength. The value of BUF at the ARO was assumed representative of the RRW. When
ERA-Interim, GFS analysis, or GEFS data was used, the RRW-mean IVT was substituted for BUF and the value of $250 \mathrm{~kg} \mathrm{~m}^{-1} \mathrm{~s}^{-1}$ was substituted for the minimum threshold. Storm-mean quantities refer to the temporal average of an ARO observation or a RRWmean quantity during AR conditions.

\section{2) CyClone DeteCtion}

Primary and secondary cyclone detection was performed using a combination of qualitative and quantitative methods. Cyclone presence and time of cyclogenesis were identified when at least one SLP isobar enclosed a pressure minimum when plotted at an interval of $2 \mathrm{hPa}$. OPC Surface analysis was used as independent verification of cyclone presence. $\mathrm{Cy}$ clone center location was assigned on the model grid (ERA-Interim, GEFS, GFS analysis) as the local minima in SLP corresponding to a qualitatively identified cyclone.

\section{3) Temperature advection}

Temperature advection $T_{\mathrm{ADV}}$ was calculated from GEFS and GFS analysis horizontal wind $\mathbf{u}$ and temperature $T$ on the $925-\mathrm{hPa}$ isobaric surface following the formula $T_{\mathrm{ADV}}=-\mathbf{u} \cdot \nabla T$.

\section{d. Forecast errors and skill}

Forecast error was calculated by subtracting the verifying analysis from the forecast. Each GEFS ensemble member provided a sample of the forecast error distribution. We evaluated forecast accuracy using the common formulae for the mean error (bias) and root-mean-square error (RMSE). Forecast uncertainty was evaluated using the error standard deviation $\sigma$ and interquartile range (IQR). Forecast skill is the forecast accuracy compared quantitatively to the accuracy of a reference. Commonly, the model climatology is used for the reference (Winterfeldt et al. 2011). Evaluations of forecast accuracy, forecast uncertainty and forecast skill were performed for a range of forecast lead times $t_{i}$, defined as the difference between forecast valid time and forecast initial time.

\section{e. Predictability limit and potential predictability}

We adopt for the definition of predictability limit the longest lead time where the forecast is more accurate than the reference (AMS 2017). Potential predictability is defined similarly, with the ensemble forecast uncertainty substituted for accuracy (Lavers et al. 2016). The primary task in evaluating forecast skill, predictability limit and potential predictability is choosing an appropriate reference, discussed next. 
a)

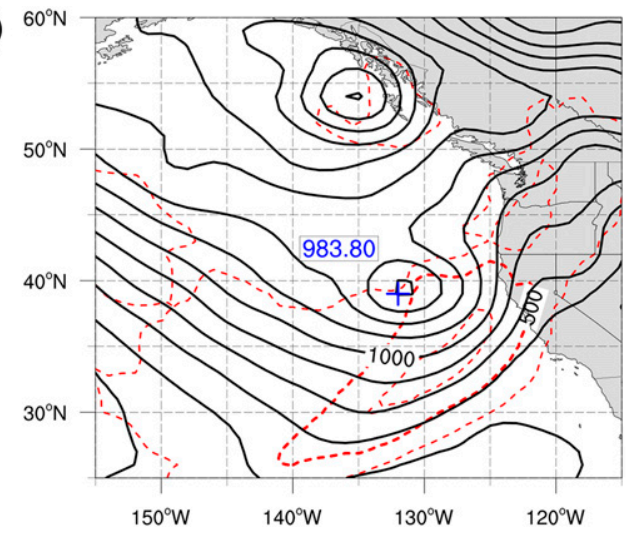

b)

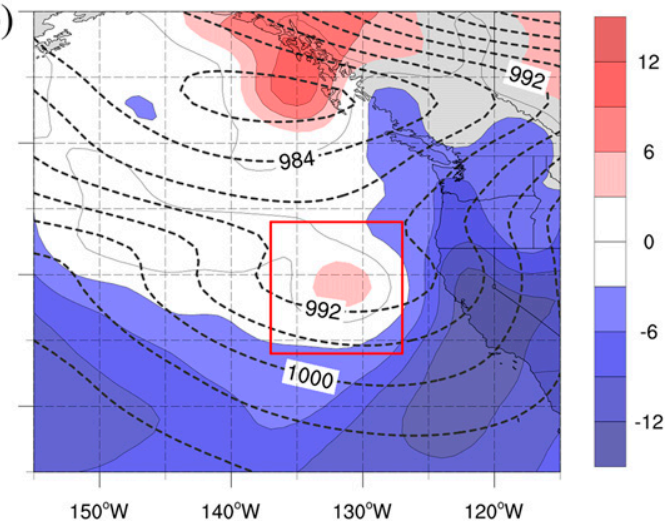

FIG. 2. (a) GFS analysis SLP (hPa; solid) and IVT $\left(\mathrm{kg} \mathrm{m}^{-1} \mathrm{~s}^{-1}\right.$; red dashed) valid at cyclogenesis: 0600 UTC 11 Dec 2014. Blue cross and text depict secondary cyclone center location and SLP (hPa), respectively. (b) Filtered GFS analysis SLP (hPa; dashed) and filtered SLP error (analysis minus filtered; $\mathrm{hPa}$; color fill). Red box encloses the cyclogenesis box used to calculate mean SLP error.

\section{f. Reference accuracy and precision}

GEFS model climatology is insufficient to resolve secondary cyclogenesis, therefore we sought an alternate definition of reference accuracy and uncertainty (jointly referred to as precision, hereafter). We followed Donohoe and Battisti (2009) in separating the SLP field into its large-scale and cyclone-scale components by means of a bandpass filter. The cyclone scale SLP was found by the relation $S_{L P} P_{C Y C}=S L P-S_{L P}$, where

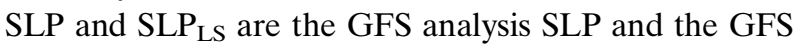
analysis SLP passed through a Butterworth filter to remove any waves smaller than approximately $20^{\circ}$ latitude in scale, respectively. SLP $_{\mathrm{CYC}}$ serves as an estimate of the error contained in a perfect forecast (the model analysis) of the large-scale pressure field. The root-mean square of SLP $_{\text {CYC }}$ in the vicinity of the secondary cyclone served as the reference precision, $\delta \mathrm{SLP}$, for this study. It was interpreted as the minimum precision in SLP necessary for GEFS to resolve secondary cyclogenesis.

Figure 2 depicts this process visually. Figure 2 a shows the GFS analysis SLP (black contours) at the time of cyclogenesis, 0600 UTC 11 December 2014. Also shown are the minimum SLP $(983.8 \mathrm{hPa})$, its location and thus the approximate center of the secondary cyclone, and the location of the AR using IVT isopleths (red dashed contours, every $250 \mathrm{~kg} \mathrm{~m}^{-1} \mathrm{~s}^{-1}$ ). Figure $2 \mathrm{~b}$ shows the fields SLP $_{\mathrm{LS}}$ (black dashed contours) and SLP $_{\mathrm{CYC}}$ (shaded). The red box in Fig. $2 b$ shows the region, a $10^{\circ}$ latitude $\times 10^{\circ}$ longitude box ("cyclogenesis box" hereafter) centered on the minimum in SLP, used to sample $\mathrm{SLP}_{\mathrm{CYC}}$ to estimate $\delta \mathrm{SLP}$. The latitude-weighted root-mean-square SLP ${ }_{\mathrm{CYC}}$ was calculated in the red box at 0000, 0600, and 1200 UTC 11 December 2014 to create the range, $2.9-4.2 \mathrm{hPa}$, of $\delta \mathrm{SLP}$.

\section{Event description}

\section{a. Evolution of weather conditions at the ARO}

Figure 3a contains a time-height profile of horizontal wind barbs measured by the ARO $449-\mathrm{MHz}$ windprofiling radar. The upper and lower altitudes of the controlling layer are shown for reference. From 1800 through 2300 UTC 10 December, controlling-layer wind speeds increased, while wind direction veered with height, indicating warm-air advection. Figure $3 b$ indicates that AR conditions began during this time period and that BUF rapidly increased. Figure $3 \mathrm{c}$ indicates that precipitation began falling at Cazadero between 1800 UTC 10 December and 0000 UTC 11 December, with a maximum hourly precipitation rate that exceeded $10 \mathrm{~mm} \mathrm{~h}^{-1}$. Between 2300 UTC 10 December and 0600 UTC 11 December, controlling-layer wind speeds (Fig. 3a) sharply decreased and winds backed with height, indicating cold-air advection. For the following $7 \mathrm{~h}$, a hiatus in AR intensification can be seen in the BUF time series (Fig. 3b). BUF sharply decreased below the minimum AR-condition threshold by 0400 UTC 11 December and the rainfall rate at Cazadero remained below $5 \mathrm{~mm} \mathrm{~h}^{-1}$ during the hiatus. After 0600 UTC 11 December, controlling-layer wind speed increased dramatically, wind direction veered with height once again, BUF rapidly increased to a peak value greater than $90 \mathrm{~cm} \mathrm{~m} \mathrm{~s}^{-1}$, and hourly precipitation at Cazadero increased to as much as $18 \mathrm{~mm} \mathrm{~h}^{-1}$.

\section{b. Evolution of weather at the synoptic scale}

The AR made initial landfall in Washington, Oregon, and California near 0000 UTC 10 December 2014. Figure 4 shows the progression of the IVT, SLP, and 300 -hPa horizontal wind speed every $12 \mathrm{~h}$ thereafter 

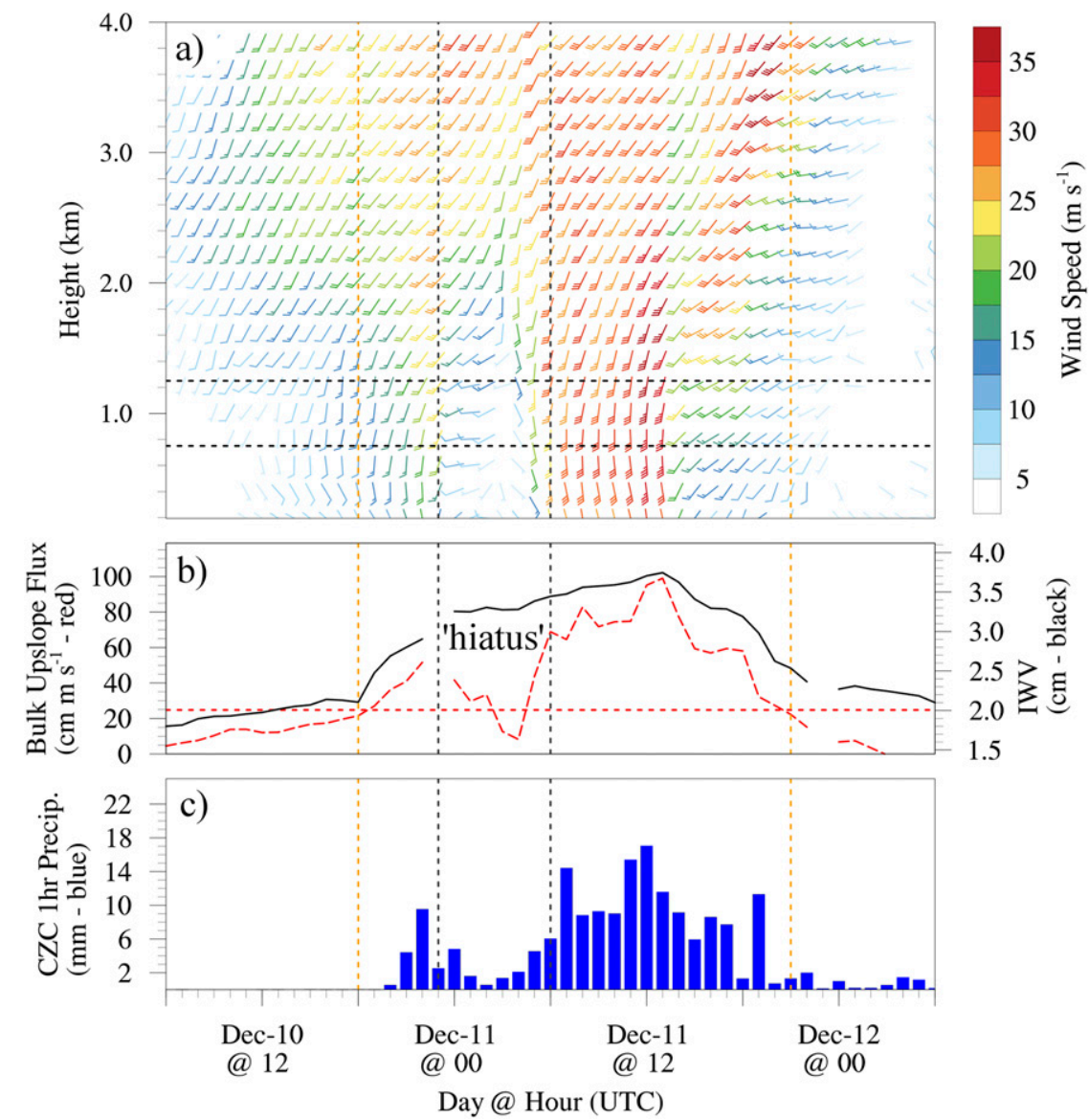

FIG. 3. (a) Time-height meteogram of horizontal wind ( $\mathrm{m} \mathrm{s}^{-1}$; barbs, color fill) at the ARO measured by 449-MHz wind-profiling radar. Horizontal dashed lines depict lower and upper altitudes of the local orographic controlling layer. (b) Time series of ARO BUF $\left(\mathrm{cm} \mathrm{m} \mathrm{s}^{-1}\right.$, red) and IWV (cm, black). Horizontal red dashed line depicts minimum flux threshold for AR conditions. (c) Time series of 1-h accumulated precipitation at CZC (mm; blue bars). In all panels, vertical orange dashed lines show the beginning and end of AR conditions as defined in Ralph et al. (2013) and vertical gray dashed lines show the beginning and end of the hiatus in AR intensification.

until peak AR conditions arrived in the RRW near 1200 UTC 11 December. The black star in Fig. 4 shows the location of the ARO, approximating the southwesternmost point in the watershed. Initially (Fig. 4a), the most intense AR band extended from $41^{\circ} \mathrm{N}, 132^{\circ} \mathrm{W}$ southwest to $30^{\circ} \mathrm{N}, 147^{\circ} \mathrm{W}$. The AR was located to the southeast of an intense trough in SLP, without closed isobar. Though this did not yet meet our definition for a cyclone, a blue "L" symbol has been placed near the minimum SLP in the trough at $49.5^{\circ} \mathrm{N}, 142^{\circ} \mathrm{W}$, indicating that a cyclone formed this location shortly after 0000 UTC 10 December. Hereafter, we will use the $\mathrm{L}\left(\mathrm{L}^{\prime}\right)$ symbol to indicate the primary (secondary) cyclone. Figure 4a also shows that the Pacific upper-tropospheric jet stream extended zonally eastward from west of the international date line to $145^{\circ} \mathrm{W}$. The AR and primary cyclone straddled the jet exit region, on the equatorward (poleward) side, respectively.

By 1200 UTC 10 December (Fig. 4b), a frontal wave appeared near the poleward periphery of the trailing end of the AR, indicated by the symbol "X." At 1200 UTC 10 December, the wave was near the bottom of a broad SLP trough and directly underneath the core of the upper-tropospheric jet streak at $36^{\circ} \mathrm{N}, 143^{\circ} \mathrm{W}$. Finally, note that by 1200 UTC 10 December, the primary cyclone deepened considerably and moved offshore of Vancouver Island.

By 0000 UTC 11 December (Fig. 4c), a clear depression in SLP formed near the new location of the wave $\left(38^{\circ} \mathrm{N}, 136^{\circ} \mathrm{W}\right)$. The deformation of the pressure gradient in this region led to a "cusp" (Ralph et al. 2011; Neiman et al. 2016) in the IVT field. Therefore, by 

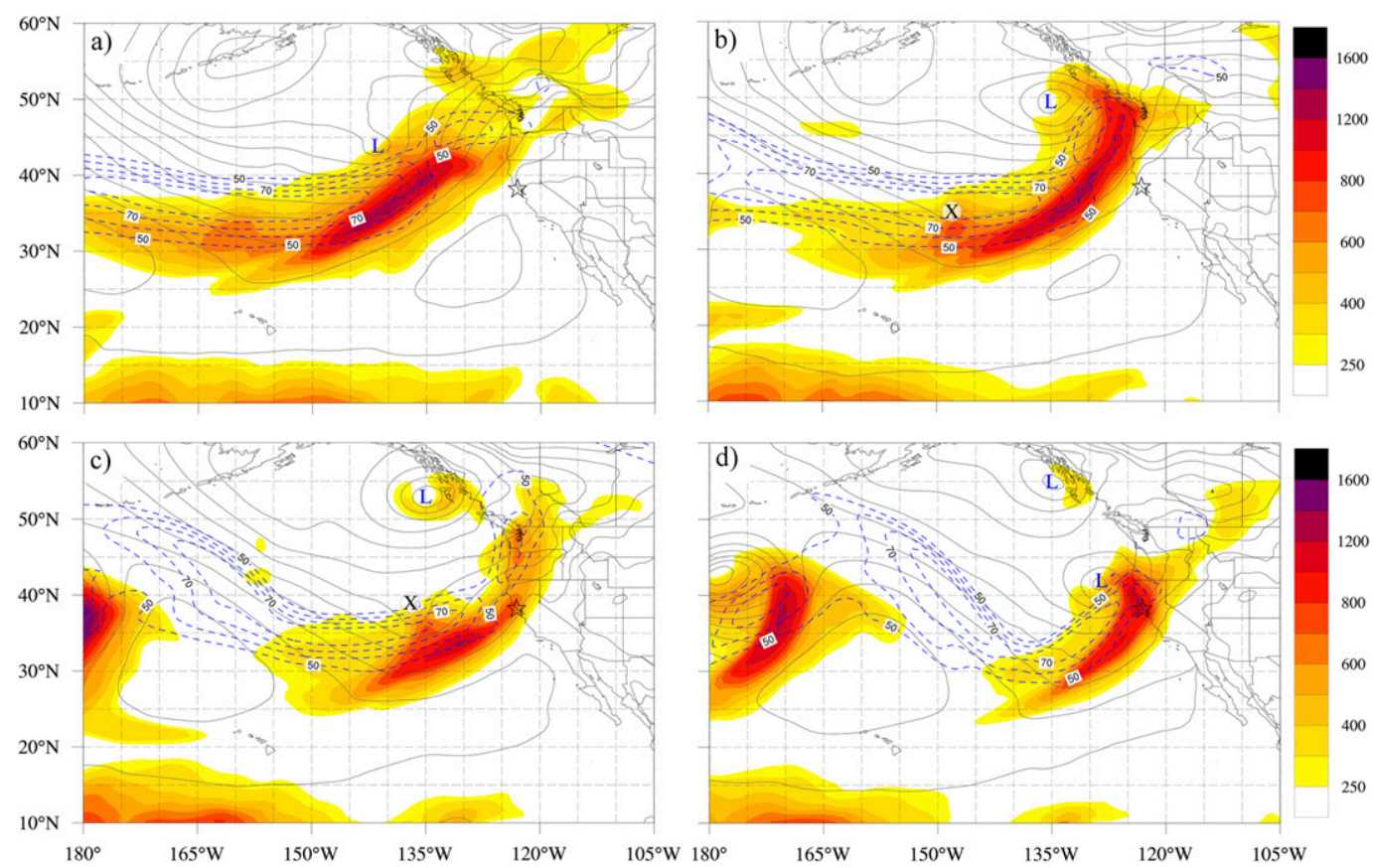

FIG. 4. (a) ERA-Interim IVT ( $\mathrm{kg} \mathrm{m}^{-1} \mathrm{~s}^{-1}$; color fill), SLP (hPa; gray solid contours every $4 \mathrm{hPa}$ from 974 to $1018 \mathrm{hPa}$ ), and 300-hPa isotachs ( $\mathrm{m} \mathrm{s}^{-1}$; blue dashed contours) valid at $0000 \mathrm{UTC} 10 \mathrm{Dec} 2014$. Location of ARO is marked by a black star. Location of primary cyclone for this event is marked by blue L. (b) As in (a), but valid at 1200 UTC 10 Dec 2014. Location of incipient MFW is marked by black X. (c) As in (b), but valid at 0000 UTC 11 Dec 2014. (d) As in (a), but valid at 1200 UTC 11 Dec 2014, and location of secondary cyclone is marked by blue L.

0000 UTC the wave feature had developed to become an MFW. The MFW was located under the poleward exit region of the upper-tropospheric jet. By 0000 UTC 11 December, Fig. 4c indicates that the AR moved southward across much of northern CA and reached the ARO and RRW. Also by 0000 UTC 11 December, the primary cyclone retrograded northwestward while the AR continued to move southeast and the upper-tropospheric jet developed significant curvature over the eastern Pacific Ocean.

By 1200 UTC 11 December, the former MFW continued to deepen. Figure 4d shows multiple closed SLP isobars and a new cyclone near $42^{\circ} \mathrm{N}, 130^{\circ} \mathrm{W}$ (hereafter referred to as the secondary cyclone). The AR was nearby the secondary cyclone, to its southeast. The AR became more meridional by 1200 UTC 11 December and remained very intense, with peak IVT that exceeded $1000 \mathrm{~kg} \mathrm{~m}^{-1} \mathrm{~s}^{-1}$ over portions of Northern CA, including the RRW. The primary cyclone stalled and began to weaken by 1200 UTC 11 December. The upper-tropospheric jet was much higher in amplitude in Fig. 4d compared to Figs. 4a-c. As in previous time steps, an upper-tropospheric jet streak remained oriented above the poleward edge of the AR. The sequence in Figs. 4b-d shows a frontal wave that began far upstream and poleward of the cold front and trailing end of the AR. The frontal wave remained in the primary cyclone cold sector and deepened as it moved toward the Pacific jet's poleward exit region, eventually developing a secondary cyclone. This wave type and secondary cyclone development pattern are similar to the class of developing frontal wave with strong upper-air support described in Parker (1998) and Ludwig et al. (2015).

\section{c. Secondary cyclogenesis}

Figure 5 synthesizes the timing of significant events at the ARO and the synoptic scale, including first detection of the secondary cyclone. Figure 5a indicates that the secondary cyclone was first detected (section 2c) at 0600 UTC 11 December. Hereafter, we will refer to this moment in time as secondary cyclogenesis. Recall from Fig. 1 that the time of secondary cyclogenesis corresponds to a significant QPF overprediction in the forecast issued on 10 December, and from Fig. 3 that this time also corresponds approximately to the end of the hiatus in AR intensification.

Figure $5 \mathrm{~b}$ shows the time series of the maximum IVT in the AR (gray solid line) and the IVT at the ARO (black dashed line). The hiatus period is visible in Fig. 5b as a plateau in ARO IVT between 0000 and 0600 UTC 11 December. Note that the maximum 


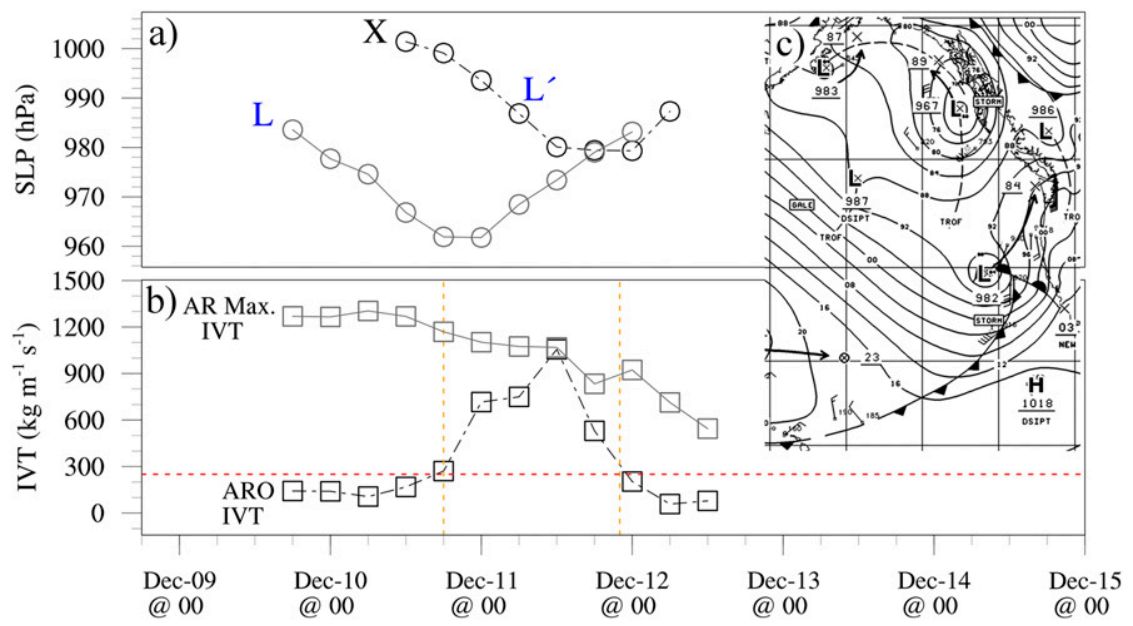

FIG. 5. Time series of (a) ERA-Interim minimum SLP (hPa) for the primary cyclone (blue L, gray solid line, and circles) and MFW (black X)/secondary cyclone (blue L'; black dashed line and circles). (b) Time series of maximum IVT $\left(\mathrm{kg} \mathrm{m}^{-1} \mathrm{~s}^{-1}\right)$ in the AR (gray solid lines and squares) and at the ARO (black dashed lines and squares). Vertical dashed orange lines depict the start and end times for AR conditions at the ARO as defined in Ralph et al. (2013). Horizontal red dashed line depicts minimum IVT threshold for AR: $250 \mathrm{~kg} \mathrm{~m}^{-1} \mathrm{~s}^{-1}$. (c) OPC surface analysis valid at 0600 UTC 11 Dec 2014 shows a developing warm front, linked to the secondary cyclone, offshore from the ARO.

value of IVT in the AR traveled over the ARO at 1200 UTC 11 December. Also note that this occurred during a spike in AR intensity at the ARO approximately $6 \mathrm{~h}$ after the hiatus ended and $6 \mathrm{~h}$ after secondary cyclogenesis. Finally, note that the wave was first detected in ERA-Interim SLP less than $6 \mathrm{~h}$ before AR conditions began at the ARO. The timing of wave detection, AR landfall in the RRW, secondary cyclogenesis, the strength of the AR, and the amount of rainfall made this event a unique forecast challenge.

The hiatus period between approximately 0000 and 0600 UTC 11 December stands out in both Fig. 3b and $5 b$. Though it occurred after the landfall of an extreme AR in the RRW and before the end of the storm; there is a clear relaxation of water vapor flux and rainfall. Perhaps most notable are the light and backing winds in the lower troposphere. Figure $5 \mathrm{c}$ is reproduced from the OPC surface analysis valid at the time of secondary cyclogenesis. The secondary cyclone is indicated with a bold $\mathrm{L}$ near the right midline of the diagram. Also indicated is a newly identified (compared to the previous analysis) warm front stretching from a frontal triple point southeast across the landfalling AR toward the San Francisco Bay Area. At this moment, the ARO was just downstream of the new warm front. Figures $5 \mathrm{a}$ and $5 \mathrm{~b}$ established that the MFW was rapidly deepening at 0000 UTC 11 December and had formed a secondary cyclone by 0600 UTC 11 December. The impact of secondary cyclogenesis and its associated warm front were as follows: After a landfalling AR began producing precipitation in the RRW through the orographic uplift of moist onshore flow, the deepening MFW and secondary cyclone deformed the existing baroclinic zones such that a shallow warm front was created offshore. This warm front acted as a hydrodynamic barrier to strong, moist lower-tropospheric winds. In the shadow of the warm front, the orographic controlling layer was briefly shielded from upslope directed vapor flux, causing a hiatus in the expected strengthening of AR conditions and rainfall as the storm came ashore. Note that during the hiatus, IWV did not decrease significantly (Fig. 3c), suggesting that wind speed and direction were affected much more than humidity. Upstream of the shallow warm front, controlling-layer vapor flux remained strong. Thus, after the warm front transited the ARO, AR conditions rapidly reestablished and heavy rains returned. Note that the hiatus seen in the IVT time series in Fig. 5b can also be explained by this mechanism. Because the warm front only created a vapor flux shadow below approximately $1.5 \mathrm{~km}$ MSL (Fig. 3a), the effect on IVT was not as severe as on BUF.

Clearly, the rapid development of the secondary cyclone and its attendant warm front affected the AR as it visited the RRW. In the next section, we will attempt to characterize GEFS skill and predictability in forecasting the secondary cyclone. We will also investigate how cyclogenesis forecast errors may have limited skill in forecasts of the $\mathrm{AR}$ and its hydrometeorological 


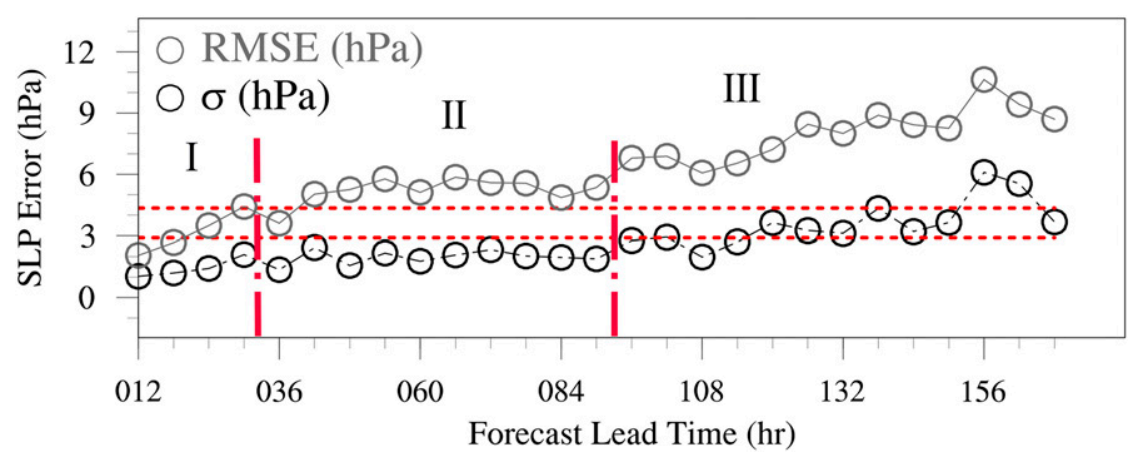

FIG. 6. GEFS predictive skill in SLP within the cyclogenesis box as a function of forecast lead time at the time of secondary cyclogenesis (0600 UTC 11 Dec 2014) as measured by RMSE (hPa; gray solid) and $\sigma$ (hPa; black dashed). Horizontal dashed red lines depict estimates of minimum precision necessary to resolve secondary cyclogenesis (see section 2). Vertical dashed-dotted red lines depict divisions between predictive skill regimes I, II, and III, respectively.

impacts, with special attention to forecasts of the developing warm front and its orographic controlling-layer shadow using the variable BUF.

\section{Analysis of forecast errors}

\section{a. Cyclogenesis predictive skill regimes}

To assess the variation in secondary cyclogenesis predictive skill with lead time, the predictability limit $(\mathrm{RMSE} \leq \delta \mathrm{SLP})$ and potential predictability $(\sigma \leq \delta \mathrm{SLP})$ were applied to GEFS forecasts within the cyclogenesis box for lead times of $12 \leq t_{i} \leq 168 \mathrm{~h}$ (Fig. 6). Based on these measures three regimes in GEFS cyclogenesis predictive skill were found. Regime I, depicted in Fig. 6 by its roman numeral and a vertical red dashed line, encompasses $t_{i} \leq 36 \mathrm{~h}$. For these lead times, GEFS SLP accuracy and uncertainty remained within or below the reference precision range. Visual inspection (not shown) of individual ensemble member forecasts showed that before 36-h lead time, a majority of members predicted a secondary cyclone near the correct location at 0600 UTC 11 December. After 36-h lead time, individual ensemble members rarely produced a secondary cyclone near the correct location at the time of cyclogenesis. This subjective analysis, paired with Fig. 6, led us to conclude that the GEFS predictability limit for this secondary cyclone was $36 \mathrm{~h}$.

Two additional predictive skill regimes fall out of the analysis in Fig. 6. For $36<t_{i} \leq 96 \mathrm{~h}$, hereafter regime II, GEFS SLP accuracy and uncertainty remained nearly fixed with lead time, and above (below) the range of $\delta$ SLP, respectively. This suggests that model errors were low enough that accurate prediction of secondary cyclogenesis was possible, but other sources of error (e.g., initial-condition error) precluded accurate predictions of secondary cyclogenesis in most regime II forecasts. Analysis of SLP errors, discussed in the next section, suggests that forecasts maintained skill in predicting the large-scale atmospheric state but generally did not accurately predict cyclogenesis in space and time during regime II. In predictive skill regime III $\left(t_{i}>96 \mathrm{~h}\right)$, GEFS RMSE increased with lead time and moved away from the minimum necessary precision. Additionally, the uncertainty in GEFS forecasts of cyclogenesis degraded, increasing beyond the range of minimum necessary precision by $150 \mathrm{~h}$. During this regime, GEFS is unable to predict cyclogenesis and skill in predicting the large-scale SLP progressively degrades.

\section{b. Biases in AR location and strength at cyclogenesis}

To assess the spatial errors in GEFS SLP and IVT, bias at the time of cyclogenesis was calculated during each predictive skill regime. During regime I (Fig. 7a), GEFS SLP bias in the vicinity of the secondary cyclone was positive, with maximum greater than $6 \mathrm{hPa}$. Downstream of the secondary cyclone, GEFS SLP bias was negative by more than $-2 \mathrm{hPa}$. This suggests that GEFS did not capture the depth of the new cyclone or the concomitant ridging downstream. The ARO and much of the RRW were near the boundary between positive and negative SLP biases. The SLP bias pattern was qualitatively similar, though amplified, during regime II (Fig. 7c).

SLP forecasts in regime III showed much greater high pressure bias $(>11 \mathrm{hPa})$ in the vicinity of the secondary cyclone (Fig. 7e), but also showed high bias near the primary cyclone $(>12 \mathrm{hPa})$. Forecast pressure in the analysis trough between the two cyclones was too low, by as much as $20 \mathrm{hPa}$. This SLP bias pattern 


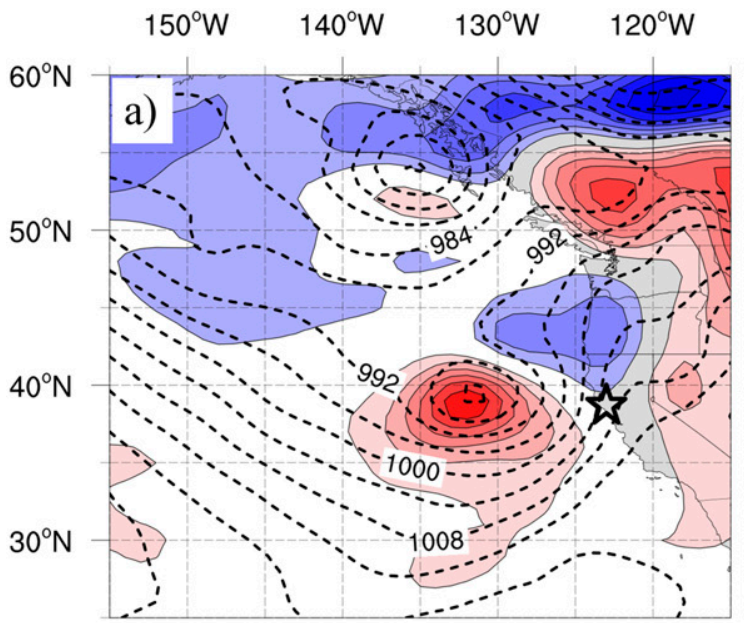

$150^{\circ} \mathrm{W} \quad 140^{\circ} \mathrm{W} \quad 130^{\circ} \mathrm{W} \quad 120^{\circ} \mathrm{W}$
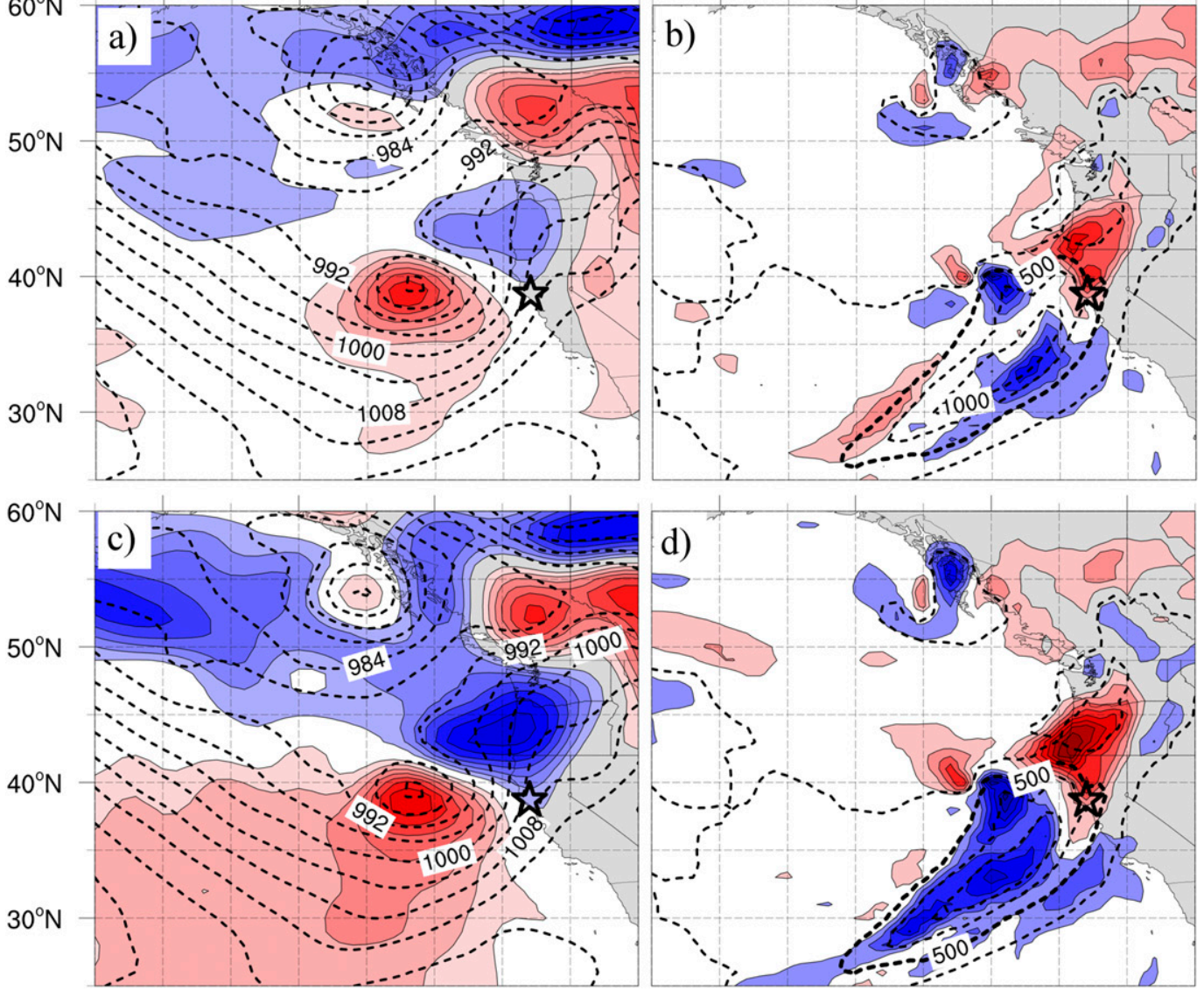

$60^{\circ} \mathrm{N}$
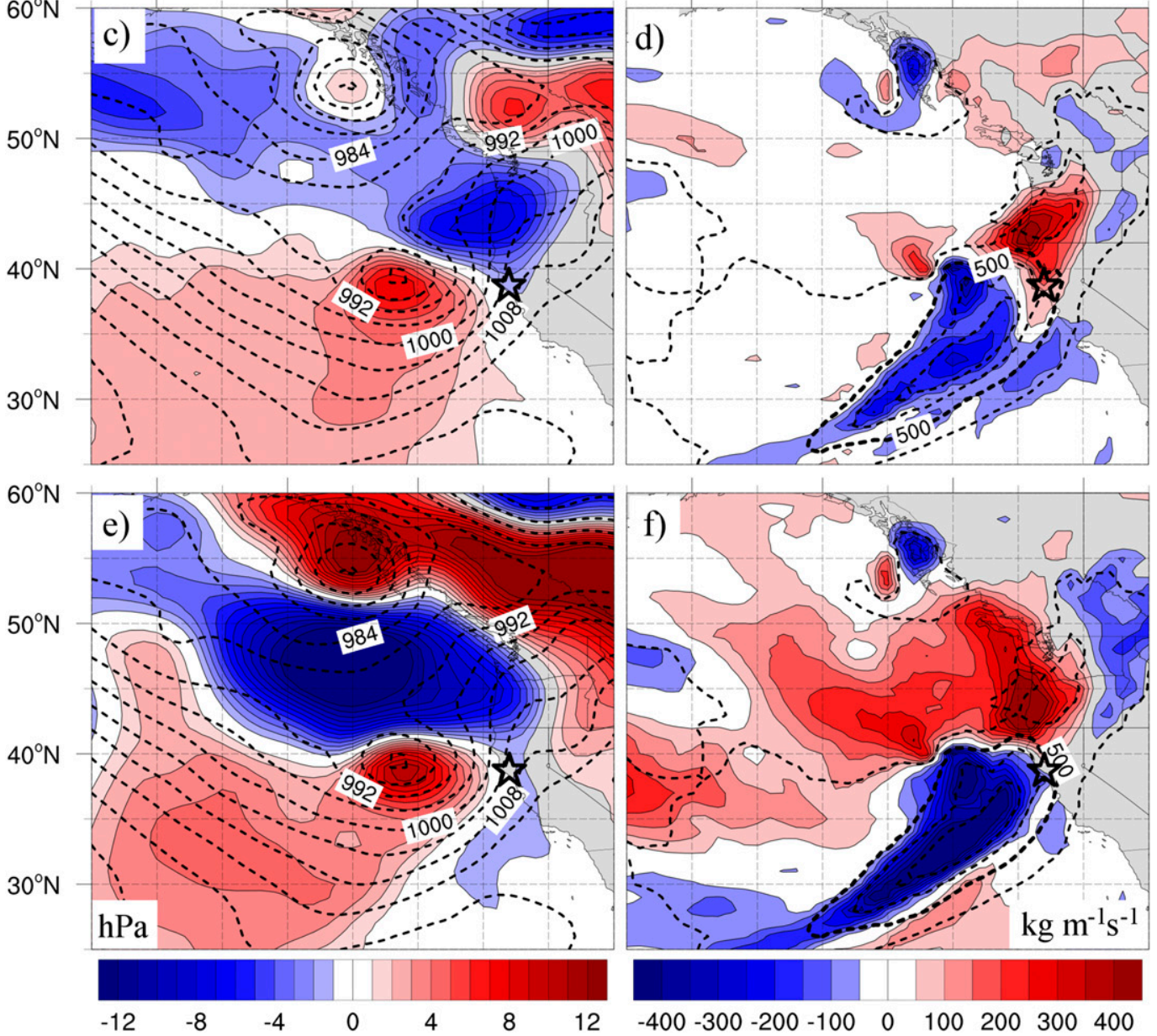

FIG. 7. (a) GEFS mean SLP error (hPa; shaded) from 24-h lead time/regime I and GEFS analysis SLP (hPa; black dashed) valid at time of secondary cyclogenesis. (b) GEFS mean IVT error $\left(\mathrm{kg} \mathrm{m}^{-1} \mathrm{~s}^{-1}\right.$; shaded) from 24-h lead time/regime I and GEFS analysis IVT $\left(\mathrm{kg} \mathrm{m}^{-1} \mathrm{~s}^{-1}\right.$; black dashed) valid at time of secondary cyclogenesis. (c) As in (a), but from 72-h lead time/regime II. (d) As in (b), but from 72-h lead time/regime II. (e) As in (a), but from 144-h lead time/regime III. (f) As in (b), but from 144-h lead time/regime III. Black star indicates ARO location. 


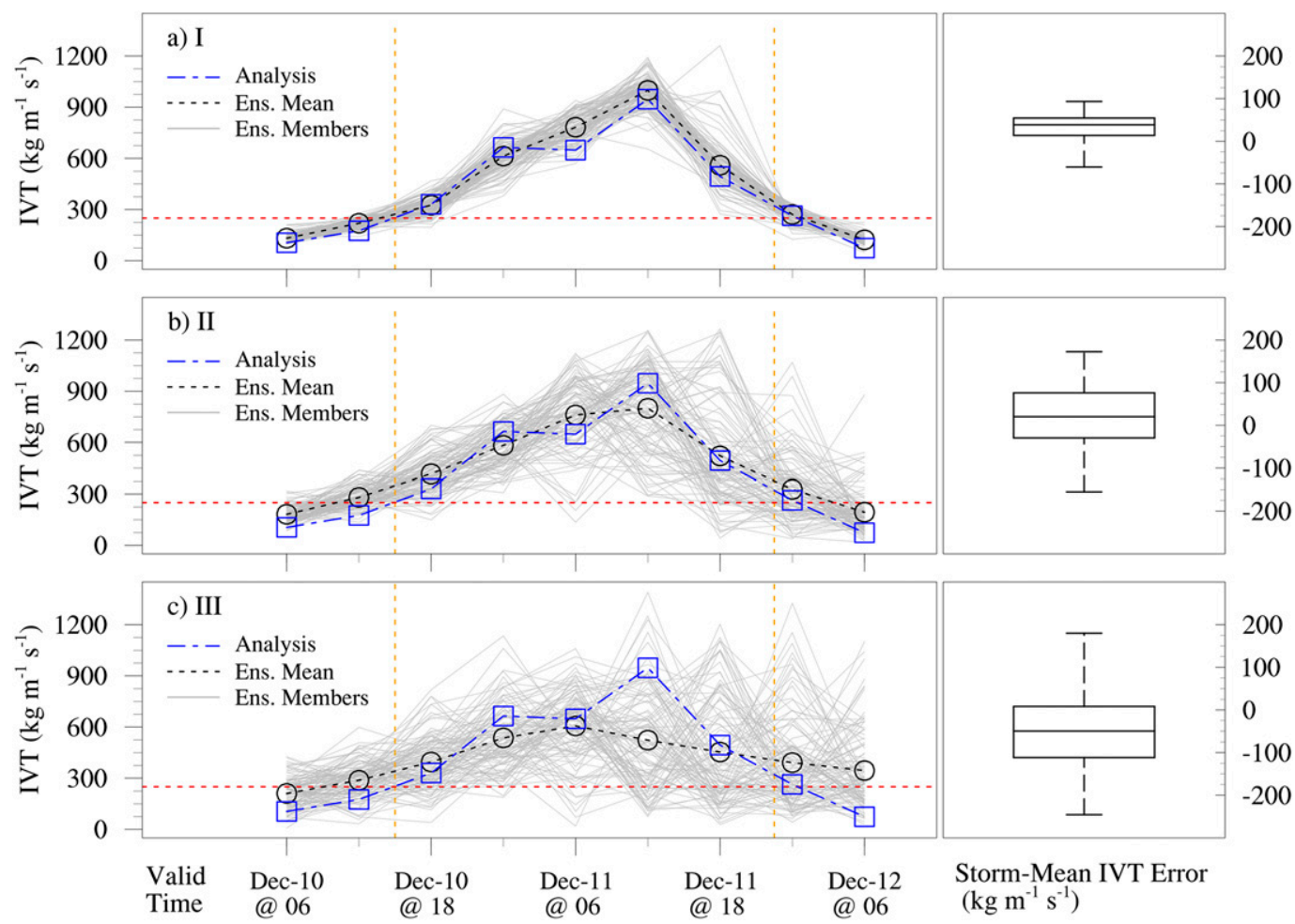

FIG. 8. (a) (left) GEFS ensemble "plume diagram" time series of RRW-mean IVT $\left(\mathrm{kg} \mathrm{m}^{-1} \mathrm{~s}^{-1}\right)$ during event from a selection of regime I forecasts. Analysis, ensemble-mean, and ensemble member IVT traces are shown in blue dashed, black dotted, and solid gray lines, respectively. Vertical orange lines depict start and end time of AR conditions at the ARO. Horizontal dashed red line depicts minimum AR threshold value of $250 \mathrm{~kg} \mathrm{~m}^{-1} \mathrm{~s}^{-1}$. (right) Storm-mean IVT error (ensemble members minus analysis). Box center, lower, and upper lines and upper and lower whiskers correspond to ensemble median, upper $25 \%$, and lower $25 \%$, and maximum and minimum values, respectively. (b) As in (a), but for selection of regime II forecasts. (c) As in (a), except for selection of regime III forecasts.

superimposed on the analysis SLP shows visually (Fig. 7e) that by regime III GEFS failed to correctly forecast the large-scale pressure pattern at the time of cyclogenesis.

The progression from regime I to regime III of GEFS IVT biases during secondary cyclogenesis (Figs. 7b,d,f) demonstrate the significant challenge in forecasting AR landfall location and intensity posed by this event. For all lead times considered, GEFS IVT biases were positive onshore and downstream of the RRW, but negative upstream in the offshore portion of the analysis AR. As GEFS lost the requisite skill to predict secondary cyclogenesis, but retained skill at predicting the large-scale pattern of baroclinicity during regime II, the predicted AR onshore and downstream intensified, while the predicted offshore AR weakened (Fig. 7d).

The IVT forecast during regime III contained large absolute biases (Fig. 7f). Within the analysis AR, forecast biases were negative (AR too weak) by $50 \%$ or greater than analysis. IVT biases downstream and to the north of the analysis AR became strongly positive by regime III, in some locations predicting AR conditions where none were found in the analysis. By regime III, the inability of GEFS to correctly predict the large-scale pressure pattern led to a false alarm for moderate to strong AR conditions (Ralph et al. 2019a) in much of Oregon, and a miss for moderate to strong AR conditions just southwest of the ARO. Past authors (Lavers et al. 2016; DeFlorio et al. 2018; Martin et al. 2018) have found a predictability limit of approximately 1 week for AR conditions. Accuracy in predicting AR conditions during this event degraded significantly by 4 days' lead time. This early degradation of forecast accuracy suggests that poor predictions of secondary cyclogenesis were a limiting factor in AR predictability.

\section{c. Errors in AR strength and duration over the RRW}

Time series of GEFS RRW-mean IVT forecasts were constructed to assess the impact of cyclogenesis predictive skill on forecasts of the AR (Fig. 8). A sample of forecasts valid every $6 \mathrm{~h}$ during the event was constructed by collecting 21 GEFS ensemble members for 
lead times in the range $\left(t_{e}-30 \mathrm{~h} \leq t_{i}<t_{e}\right)$, where $t_{e}$ is the maximum lead time in each predictive skill regime (Fig. 6). Watershed-mean IVT forecasts during regime I (Fig. 8a) displayed relatively little error. Storm-mean error IQR varied from 0 to $50 \mathrm{~kg} \mathrm{~m}^{-1} \mathrm{~s}^{-1}$, or less than $8 \%$ of the storm-mean analysis IVT. GEFS mean IVT was not appreciably different than analysis IVT during AR conditions apart from secondary cyclogenesis at 0600 UTC 11 December. As noted in Fig. 5b, this corresponded to a hiatus in AR intensification over the RRW that was not captured by the GEFS ensemble forecasts in any of the predictive skill regimes. Despite this error, the forecast timing of AR condition start, peak AR intensity and AR condition end over the RRW were accurate compared to analysis during regime I forecasts.

Watershed-mean IVT forecast uncertainty increased significantly as lead times lengthened from regime I to II (Fig. 8b). Storm-mean forecast error IQR doubled to encompass the range from -25 to $75 \mathrm{~kg} \mathrm{~m}^{-1} \mathrm{~s}^{-1}$. In contrast to regime $\mathrm{I}$, the spread of ensemble member forecasts sometimes included an AR-condition miss (ensemble members dipped below the red line in Fig. 8b). While forecast uncertainty increased in regime II, forecasts of watershed-mean IVT remained unbiased. This is confirmed visually by the ensemble member and mean time series relative to the analysis, and by the stormmean, ensemble-median forecast error in the right inset of Fig. 8b. The ensemble-mean IVT forecasts performed well, not different than the analysis by more than $15 \%$. The ensemble-mean IVT forecasts in regime II precisely forecasted the timing of peak AR intensity; however, the reader will note that the ensemble-mean IVT called for AR condition to start as much as $6 \mathrm{~h}$ earlier than and as much as $3 \mathrm{~h}$ later than the analysis.

Regime III GEFS forecasts showed further increase in IVT uncertainty compared to regimes I and II. Stormmean forecast error IQR included the range from -120 to $10 \mathrm{~kg} \mathrm{~m}^{-1} \mathrm{~s}^{-1}$, while ensemble outliers spanned the range from -250 to $175 \mathrm{~kg} \mathrm{~m}^{-1} \mathrm{~s}^{-1}$, or $66 \%$ of the stormmean analysis IVT. Regime III ensemble-mean forecasts severely underforecast peak AR intensity over the RRW. While the analysis AR reached peak intensity of $1000 \mathrm{~kg} \mathrm{~m}^{-1} \mathrm{~s}^{-1}$ at 1200 UTC 11 December, the GEFS mean forecast AR reached only $600 \mathrm{~kg} \mathrm{~m}^{-1} \mathrm{~s}^{-1}$ at 0600 UTC 11 December. Early arrival of peak AR intensity was not the only error in forecast timing during regime III. Ensemble-mean AR conditions were forecast to last more than $15 \mathrm{~h}$ longer than the analysis storm.

The failure of GEFS to skillfully predict secondary cyclogenesis for lead times greater than $36 \mathrm{~h}$ did not immediately lead to poor forecasts of AR conditions in the RRW. For regime II lead times $\left(36<t_{i} \leq 96 \mathrm{~h}\right)$,
GEFS mean forecasts of IVT in the watershed performed well, with near-zero bias. However, the lack of secondary cyclone in forecasts in this regime, as well as the failure to correctly forecast the ridge downstream of the cyclone coincided with a large increase in IVT forecast uncertainty. IVT forecasts downstream of the RRW were additionally too strong. For the longer lead times of regime III, GEFS could not skillfully predict cyclogenesis and the ensemble mean no longer qualitatively matched the larger scale atmospheric pressure pattern. Notably, rather than robust primary and secondary cyclones, GEFS predicted a deeper broad trough in the near-continental northeastern Pacific. Coinciding with these large-scale SLP errors, GEFS predicted landfalling AR conditions too far to the north, and predicted an AR over the RRW that was longer and weaker than observed with peak intensity that occurred too early. We will now turn our attention to the forecast errors related to the secondary cyclone's shallow warm front and how forecasts of BUF in its shadow were impacted during regime I.

\section{d. Forecasts of the warm front and the orographic controlling layer}

Figure 9a shows the GFS analysis 925-hPa horizontal temperature advection (color fill) and wind barbs at 0600 UTC 11 December. The developing warm front appears as the poleward edge of an arc where $T_{\mathrm{ADV}}>$ $4 \mathrm{~K}(6 \mathrm{~h})^{-1}$. This arc extended from the secondary cyclone's center of circulation southeastward toward $33^{\circ} \mathrm{N}$, $123^{\circ} \mathrm{W}$. The warm front was just reaching the ARO at 0600 UTC 11 December. The arc of warm-air advection stood in sharp contrast to surrounding regions downstream of the cyclone and to the broad region of cold-air advection that trailed the cold front southwest of $43^{\circ} \mathrm{N}$, $130^{\circ} \mathrm{W}$. A very sharp gradient between warm- and coldair advection was developing across the existing AR, just offshore from the ARO. The resulting temperature tendency would have deformed isentropic surfaces here, promoting the lifting of AR air parcels before they reach the CA coast, ARO, and RRW.

Figure $9 \mathrm{~b}$ shows the GEFS RMSE and $\sigma$ in regime I forecasts of $925-\mathrm{hPa} T_{\mathrm{ADV}}$. Forecast error and uncertainty were greatest in the region upstream of the warm front, near the maximum in analysis warm-air advection. The local maxima in $\sigma$ here indicates low predictability in the developing warm-frontal region, even for small $\left(t_{i} \leq 36 \mathrm{~h}\right)$ forecast lead time. The forecast error in the developing warm-frontal region was similar in magnitude $\left[6-8 \mathrm{~K}(6 \mathrm{~h})^{-1}\right]$ to the analysis values. Climatological temperature advection forecasts (values of zero) would have performed with similar accuracy, indicating that predictive skill was already lost 
a) $\quad 150^{\circ} \mathrm{W} \quad 140^{\circ} \mathrm{W} \quad 130^{\circ} \mathrm{W} \quad 120^{\circ} \mathrm{W}$

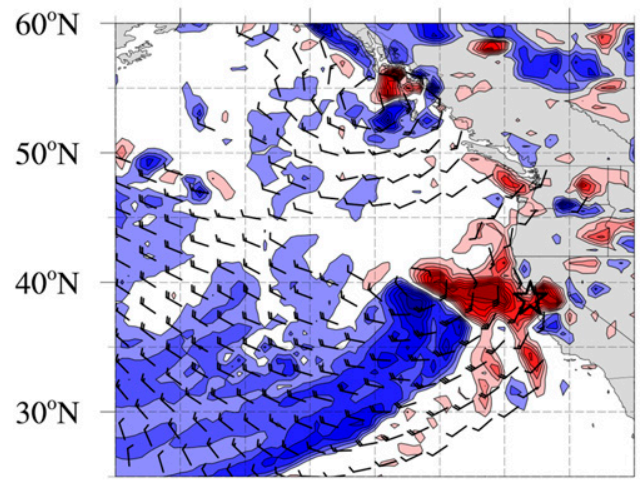

b) $150^{\circ} \mathrm{W} \quad 140^{\circ} \mathrm{W} \quad 130^{\circ} \mathrm{W} \quad 120^{\circ} \mathrm{W}$
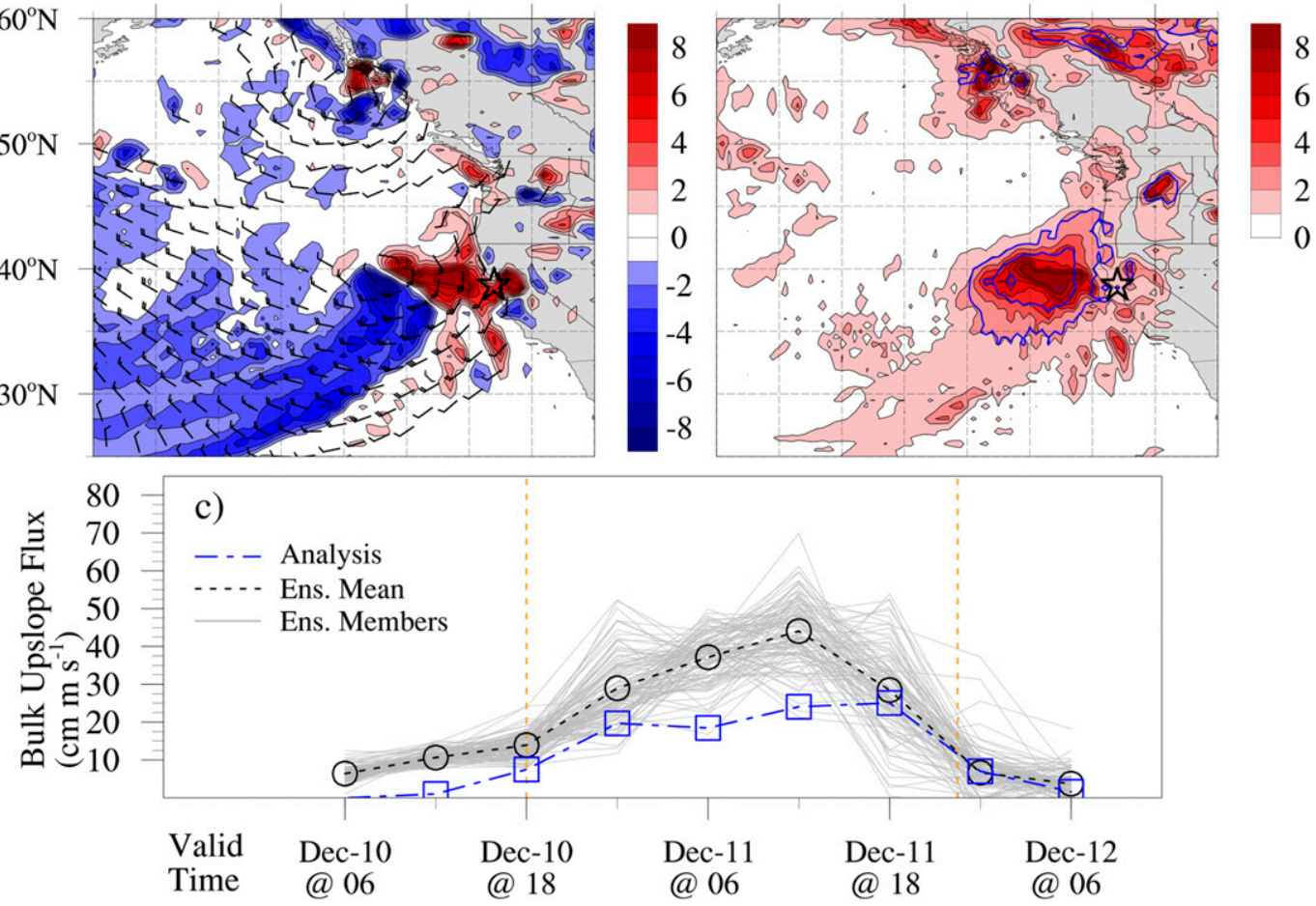

FIG. 9. (a) GFS analysis 925 -hPa temperature advection $\left[\mathrm{K}(6 \mathrm{~h})^{-1}\right.$; color fill $]$ and 925 -hPa horizontal wind ( $\mathrm{m} \mathrm{s}^{-1}$; wind barbs) at 0600 UTC 11 Dec 2014. Star shows location of ARO. (b) As in (a), but GEFS forecast RMSE $\left[\mathrm{K}(6 \mathrm{~h})^{-1}\right.$; color fill $]$ and $\sigma\left[\mathrm{K}(6 \mathrm{~h})^{-1}\right.$; blue contours from 2 to $6 \mathrm{~K}(6 \mathrm{~h})^{-1}$, every $\left.2 \mathrm{~K}(6 \mathrm{~h})^{-1}\right]$ of error in temperature advection. (c) Time-lagged/GEFS ensemble plume diagram of RRW-mean BUF $\left(\mathrm{cm} \mathrm{m} \mathrm{s}^{-1}\right)$ during event from a selection of regime I forecasts. Analysis, ensemble-mean, and ensemble member forecasts are shown in blue dashed, black dotted, and solid gray lines, respectively. Vertical orange lines depict start and end time of AR conditions at the ARO.

for $925-\mathrm{hPa} T_{\mathrm{ADV}}$ during regime I. Though we found that GEFS retained the ability to skillfully predict secondary cyclogenesis during regime I, the same cannot be said for forecasts of the secondary cyclone's warm front.

The resulting skill in regime I GEFS forecasts of RRW-mean BUF is shown in Fig. 9c. The ensemblemean forecast was too high for all times valid during AR conditions. Near secondary cyclogenesis (06001200 UTC 11 December), mean forecast BUF was more than double the analysis value. As we saw in Figs. 8a-c, forecasts failed to capture the hiatus in intensification between 0000 and 0600 UTC 11 December. While IVT forecasts during regime I were reasonably accurate (Fig. 8a), forecasts of BUF were strongly impacted by the inability of GEFS to predict the rapid development of a warm front crossing the offshore portion of the landfalling AR. Forecast errors in BUF were highest (near $100 \%$ relative to analysis) during the period 0600 1200 UTC 11 December. This corresponded to the 12-h enclosing secondary cyclogenesis. Together with Figs. 9a and $9 b$, we find that forecast errors in BUF peaked during the period when the warm front shadowed the RRW controlling layer from moist upslope flow, and that these peak errors were likely caused by the failure of GEFS to correctly forecast the developing warm front. Because BUF at the ARO is commonly used as a situational awareness tool (Ralph et al. 2013; White et al. 2013) by CNRFC forecasters during AR events in the Russian River watershed, it is likely that the strong regime I overforecast of BUF influenced the 10 December river-stage forecasts at Guerneville (Fig. 1d).

\section{Review and discussion of findings}

We presented the case of an extreme AR that impacted Washington, Oregon, and Northern CA. As the AR made landfall in the RRW, an incipient frontal wave traveled near the AR-cold-frontal boundary and underneath the poleward exit region of the Pacific uppertropospheric jet (Fig. 4). During AR conditions in the watershed, the wave rapidly developed a secondary 
cyclone. Observations and model analyses (Figs. 3 and 5) make it clear that secondary cyclogenesis significantly impacted the landfalling AR. Cyclogenesis corresponded to a hiatus in the intensification of AR conditions. During the hiatus, rainfall slackened in the watershed, though tropospheric moisture content did not (Fig. 3). In part, this hiatus was caused by the shadowing of the orographic-precipitation controlling layer by a shallow warm front (Fig. 5). The shallow warm front also rapidly developed during the cyclogenesis period. After cyclogenesis and after the warm front transited the RRW, AR conditions rapidly strengthened again, and the most intense part of the AR briefly visited the watershed (Fig. 5), leading to extreme AR conditions. Streamflow forecasts for the lower Russian River likewise rapidly increased as the AR made landfall (Fig. 1), demonstrating that this event was highly uncertain even for experienced human forecasters.

GEFS SLP forecasts were unable to skillfully predict secondary cyclogenesis for lead times greater than $36 \mathrm{~h}$ (Fig. 6). For longer lead times (herein referred to as regimes II and III), the failure to predict secondary cyclogenesis led to significant forecast uncertainty in landfalling-AR intensity and led to a long bias in forecast AR duration (Fig. 8). For forecast lead times longer than $96 \mathrm{~h}$, the forecast AR becomes significantly weak, and landfalling-AR location errors are large with moderate or strong AR conditions incorrectly forecasted for much of Oregon and missed for much of Northern CA (Fig. 7).

IVT was overforecast during regime I. This overforecast was caused by the failure of GEFS to capture the AR intensification hiatus. Nonetheless, the effect on IVT, a troposphere-integrated quantity, is small (Fig. 8). More significant is the failure of GEFS to capture structural details of the secondary cyclone, in this case a shallow warm front intersecting the offshore portion of the AR (Fig. 9a). GEFS did not demonstrate predictive skill in forecasts of warm-air advection near the warm front at any lead time (Fig. 9b). The lack of predictive skill relative to the warm front led to large overprediction of BUF in the watershed and thus led to forecasts with orographic rainfall potential that was much too high (Fig. 9c).

The AR and secondary cyclone studied herein present additional challenges to the forecaster because they are a sequence of rare events. The RRW can expect to experience extreme AR conditions one or two times in any given year (Ralph et al. 2019b). Of those rare instances, a fraction will have mesoscale frontal waves, and a smaller fraction of mesoscale frontal waves will develop into secondary cyclones. Forecasts of runoff and streamflow are additionally sensitive to smaller-scale hydrometeorological details such as orographic precipitation forcing. The final rare event described herein, a new warm front shadowing the watershed from moist upslope flow while a significant portion of the AR remained offshore, carries such low intrinsic predictability (Fig. 9b) that near-term improvements in numerical weather prediction are unlikely to alleviate the potential for errors in similar situations. Nonetheless, improvements in situational awareness and the development of climatologies of ARs, MFWs, and secondary cyclones may significantly improve human forecaster ability to anticipate challenging flood scenarios such as this one in the future. This study highlights the need to characterize and account for bias and uncertainty related to mesoscale waves and secondary cyclones in short- and medium-range hydrometeorological forecasts. A first step may be applying robust objective identification techniques to build climatologies, including overlap with significant AR for the U.S. West Coast.

Acknowledgments. The U.S. Army Corps of Engineers Award W912HZ-15-SOI-0019 provided financial support for this research. The authors thank the California Nevada River Forecast Center for guidance on data access and formats and for discussion of forecast procedures. Special thanks also to Dr. David Lavers of the European Centre for Medium Range Weather Forecasting, Dr. David Reynolds of the Cooperative Institute for Research in Environmental Sciences, Dr. Jonathan Rutz of the National Weather Service Western Region Headquarters, and Drs. Julie Kalansky and Robert Hartman of the Center for Western Weather and Water Extremes for many fruitful discussions during analysis and writing of this work.

\section{REFERENCES}

AMS, 2017: Predictability limit. Glossary of Meteorology. URL http://glossary.ametsoc.org/wiki/Predictability_limit.

Cordeira, J. M., F. M. Ralph, and B. J. Moore, 2013: The development and evolution of two atmospheric rivers in proximity to western north pacific tropical cyclones in October 2010. Mon. Wea. Rev., 141, 4234-4255, https://doi.org/10.1175/ MWR-D-13-00019.1.

Dee, D. P., and Coauthors, 2011: The ERA-Interim reanalysis: Configuration and performance of the data assimilation system. Quart. J. Roy. Meteor. Soc., 137, 553-597, https://doi.org/ 10.1002/qj.828.

DeFlorio, M. J., D. E. Waliser, B. Guan, D. A. Lavers, F. M. Ralph, and F. Vitart, 2018: Global assessment of atmospheric river prediction skill. J. Hydrometeor., 19, 409-426, https://doi.org/ 10.1175/JHM-D-17-0135.1.

Dettinger, M. D., F. M. Ralph, T. Das, P. J. Neiman, and D. R. Cayan, 2011: Atmospheric rivers, floods and the water resources of California. Water, 3, 445-478, https://doi.org/ 10.3390/w3020445. 
Donohoe, A., and D. S. Battisti, 2009: The amplitude asymmetry between synoptic cyclones and anticyclones: Implications for filtering methods in feature tracking. Mon. Wea. Rev., 137, 3874-3887, https://doi.org/10.1175/2009MWR2837.1.

Fink, A. H., S. Pohle, J. G. Pinto, and P. Knippertz, 2012: Diagnosing the influence of diabatic processes on the explosive deepening of extratropical cyclones. Geophys. Res. Lett., 39, https://doi.org/10.1029/2012GL051025.

Guan, B., and D. E. Waliser, 2015: Detection of atmospheric rivers: Evaluation and application of an algorithm for global studies. J. Geophys. Res. Atmos., 120, 12 514-12535, https://doi.org/ 10.1002/2015JD024257.

Hewson, T. D., 2009: Diminutive frontal waves-a link between fronts and cyclones. J. Atmos. Sci., 66, 116-132, https://doi.org/ 10.1175/2008JAS2719.1.

Lavers, D. A., D. E. Waliser, F. M. Ralph, and M. D. Dettinger, 2016: Predictability of horizontal water vapor transport relative to precipitation: Enhancing situational awareness for forecasting western us extreme precipitation and flooding. Geophys. Res. Lett., 43, 2275-2282, https://doi.org/10.1002/ 2016GL067765.

Leung, L. R., and Y. Qian, 2009: Atmospheric rivers induced heavy precipitation and flooding in the western us simulated by the WRF regional climate model. Geophys. Res. Lett., 36, L03820, https://doi.org/10.1029/2008GL036445.

Ludwig, P., J. G. Pinto, S. A. Hoepp, A. H. Fink, and S. L. Gray, 2015: Secondary cyclogenesis along an occluded front leading to damaging wind gusts: Windstorm Kyrill, January 2007. Mon. Wea. Rev., 143, 1417-1437, https://doi.org/10.1175/ MWR-D-14-00304.1.

Martin, A., F. M. Ralph, R. Demirdjian, L. DeHaan, R. Weihs, J. Helly, D. Reynolds, and S. Iacobellis, 2018: Evaluation of atmospheric river predictions by the WRF model using aircraft and regional mesonet observations of orographic precipitation and its forcing. J. Hydrometeor., 19, 1097-1113, https://doi.org/10.1175/JHM-D-17-0098.1.

Nayak, M. A., G. Villarini, and D. A. Lavers, 2014: On the skill of numerical weather prediction models to forecast atmospheric rivers over the central united states. Geophys. Res. Lett., $\mathbf{4 1}$, 4354-4362, https://doi.org/10.1002/2014GL060299.

Neiman, P. J., F. M. Ralph, A. White, D. Kingsmill, and P. Persson, 2002: The statistical relationship between upslope flow and rainfall in California's coastal mountains: Observations during CALJET. Mon. Wea. Rev., 130, 1468-1492, https://doi.org/ 10.1175/1520-0493(2002)130<1468:TSRBUF $>2.0$. CO;2.

, A. B. White, F. M. Ralph, D. J. Gottas, and S. I. Gutman, 2009: A water vapour flux tool for precipitation forecasting. Proc. Inst. Civ. Eng.: Water Manage., 162, 83-94, https:// doi.org/10.1680/wama.2009.162.2.83.

— L. J. Schick, F. M. Ralph, M. Hughes, and G. A. Wick, 2011: Flooding in western Washington: The connection to atmospheric rivers. J. Hydrometeor., 12, 1337-1358, https://doi.org/ 10.1175/2011JHM1358.1.

, F. M. Ralph, B. J. Moore, M. Hughes, K. M. Mahoney, J. M. Cordeira, and M. D. Dettinger, 2013: The landfall and inland penetration of a flood-producing atmospheric river in Arizona. Part I: Observed synoptic-scale, orographic, and hydrometeorological characteristics. J. Hydrometeor., 14, 460-484, https://doi.org/10.1175/JHM-D-12-0101.1.

, B. J. Moore, A. B. White, G. A. Wick, J. Aikins, D. L. Jackson, J. R. Spackman, and F. M. Ralph, 2016: An airborne and ground-based study of a long-lived and intense atmospheric river with mesoscale frontal waves impacting California during Calwater-2014. Mon. Wea. Rev., 144, 1115-1144, https://doi.org/ 10.1175/MWR-D-15-0319.1.

Parker, D., 1998: Secondary frontal waves in the North Atlantic region: A dynamical perspective of current ideas. Quart. J. Roy. Meteor. Soc., 124, 829-856, https://doi.org/10.1002/ qi.49712454709.

Ralph, F. M, and M. Dettinger, 2011: Storms, floods, and the science of atmospheric rivers. Eos, Trans. Amer. Geophys. Union, 92, 265-266, https://doi.org/10.1029/2011EO320001.

Ralph, F. M., P. J. Neiman, G. A. Wick, S. I. Gutman, M. D. Dettinger, D. R. Cayan, and A. B. White, 2006: Flooding on California's Russian River: Role of atmospheric rivers. Geophys. Res. Lett., 33, L13801, https://doi.org/10.1029/2006GL026689.

, G. N. Kiladis, K. Weickmann, and D. W. Reynolds, 2011: A multiscale observational case study of a Pacific atmospheric river exhibiting tropical-extratropical connections and a mesoscale frontal wave. Mon. Wea. Rev., 139, 1169-1189, https://doi.org/10.1175/2010MWR3596.1.

— T. Coleman, P. Neiman, R. Zamora, and M. Dettinger, 2013: Observed impacts of duration and seasonality of atmosphericriver landfalls on soil moisture and runoff in coastal Northern California. J. Hydrometeor., 14, 443-459, https://doi.org/ 10.1175/JHM-D-12-076.1.

— J. J. Rutz, J. M. Cordeira, M. Dettinger, M. Anderson, D. Reynolds, L. J. Schick, and C. Smallcomb, 2019a: A scale to characterize the strength and impacts of atmospheric rivers. Bull. Amer. Meteor. Soc., 100, 269-289, https://doi.org/ 10.1175/BAMS-D-18-0023.1.

— , and Coauthors, 2019b: ARTMIP-early start comparison of atmospheric river detection tools: how many atmospheric rivers hit northern California's Russian River watershed? Climate Dyn., 52, 4973-4994, https://doi.org/10.1007/s00382018-4427-5.

Renfrew, I. A., A. J. Thorpe, and C. H. Bishop, 1997: The role of the environmental flow in the development of secondary frontal cyclones. Quart. J. Roy. Meteor. Soc., 123, 1653-1675, https://doi.org/10.1002/qj.49712354210.

White, A., and Coauthors, 2013: A twenty-first-century California observing network for monitoring extreme weather events. J. Atmos. Oceanic Technol., 30, 1585-1603, https://doi.org/ 10.1175/JTECH-D-12-00217.1.

Wick, G. A., P. J. Neiman, F. M. Ralph, and T. M. Hamill, 2013: Evaluation of forecasts of the water vapor signature of atmospheric rivers in operational numerical weather prediction models. Wea. Forecasting, 28, 1337-1352, https://doi.org/ 10.1175/WAF-D-13-00025.1.

Winterfeldt, J., B. Geyer, and R. Weisse, 2011: Using QuikSCAT in the added value assessment of dynamically downscaled wind speed. Int. J. Climatol., 31, 1028-1039, https://doi.org/10.1002/ joc. 2105 . 